\title{
Role of Particle-Matrix Interface in the Deformation and Fracture Behaviour of Filled Epoxy Resins
}

\author{
Tony Kaiser*
}

Abstract. As a result of their superior mechanical, chemical, and electrical properties particulate-filled epoxies are finding widespread use in the fabrication of a large number of engineering components, one important example being as electrical insulators for the power industry. Since these materials are mainly subjected to continuous mechanical loads (in addition to a continuous dielectrical stress), there is an apparent need first to understand and then to predict the processes of deformation and fracture during longterm loading conditions. A few years ago, the respective material science knowledge was very limited, and design was mainly based on experience and purely empirical work. During recent years, however, a rather comprehensive understanding of the short and long-term deformation and fracture behaviour of these brittle, highly cross-linked polymers, especially of silica-filled anhydride-cured epoxies, has been accumulated. This holds particularly for the understanding of their creep behaviour, i.e. the deformation-induced volume damage and the mechanisms which are responsible for creep failure. In this article, a survey will given on the applications, and the deformation and fracture behaviour of particulate-epoxies. In particular, the role of particle-matrix interface in connexion with deformation, fracture, and creep behaviour and the related deformation-induced volume damage is discussed. A complete understanding of the role of the particle-matrix interface is still lacking and, therefore, a coherent description is not possible, and the true practical value of a filler surface treatment is not yet known. However, the following can be said: local as well as global debonding between matrix and filler should be prevented; local debonding tends to act as a critical flaw (in a fracture mechanics sense) and leads to brittle failure. Global debonding is equivalent to creep damage and leads to premature failure of the respective component.

\section{Applications of Particulate-Epoxies in Electrical Engineering}

Epoxy resins, in particular silica-filled epoxy casting resins, have been extensively used in electrical engineering for more than two decades. These materials combine an excellent thermo-mechanical and electrical performance with advantageous processing properties. They have substantially contributed to the breakthrough of novel technologies in power engineering, in highvoltage motor, and generator manufacturing as well as in high-voltage switchgear and substation technology. The most striking example is in $\mathrm{SF}_{6}$-technology. The excellent dielectric strengths of $\mathrm{SF}_{6}$ gas and particulate and fibre-reinforced epoxies have enabled the engineer to build highvoltage switchgear stations with only a few percents of the space needed for a conventional air-insulated substation. An example of such a switchgear is shown in Fig. I, a corresponding particulate reinforced epoxy insulator in Fig. 2.

In such applications, epoxy resins often are not only subjected to high electrical fields but also to elevated temperatures up to $100^{\circ}$ and rather high mechanical loads.

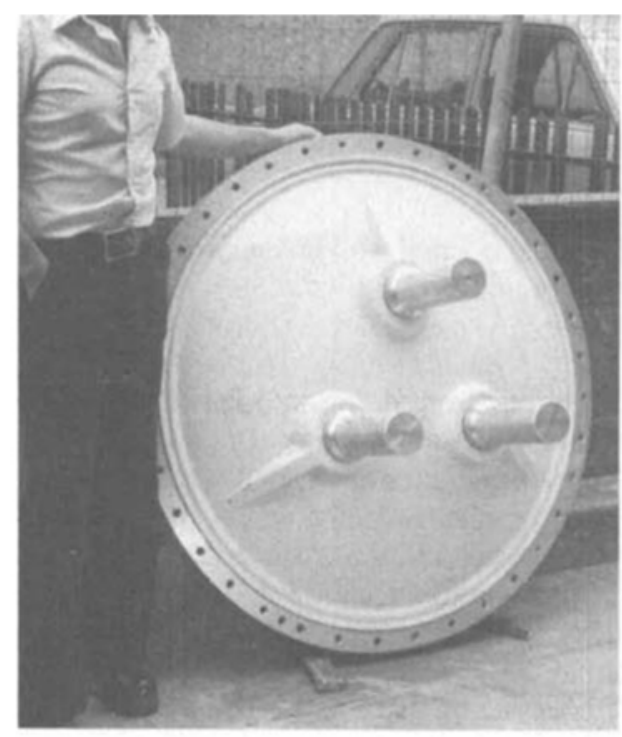

Fig. 2. Example of a three-phase cpoxy insulator for GIS

anisms), was rather poor. As a consequence, a strong stimulation for materials science research in epoxy resins during recent years has come from electrical engineering [1-3]. All these examinations showed that interfacial failure (debonding between filler particle and epoxy matrix) is involved in many processes, e.g. debonding plays a central role in yielding, crack initiation, crack propagation, creep damage, and failure of silica-filled epoxies. Macroscopically, debonding appears as 'stresswhitening'.

This paper will first summarize the general understanding of particle-matrix adhesion and its relevance for various macroscopic properties. Then, two sections will focus in detail on the role of interface and interfacial adhesion in crack growth and in creep failure. Finally, some conclusions haviour (creep damage, creep failure mech-

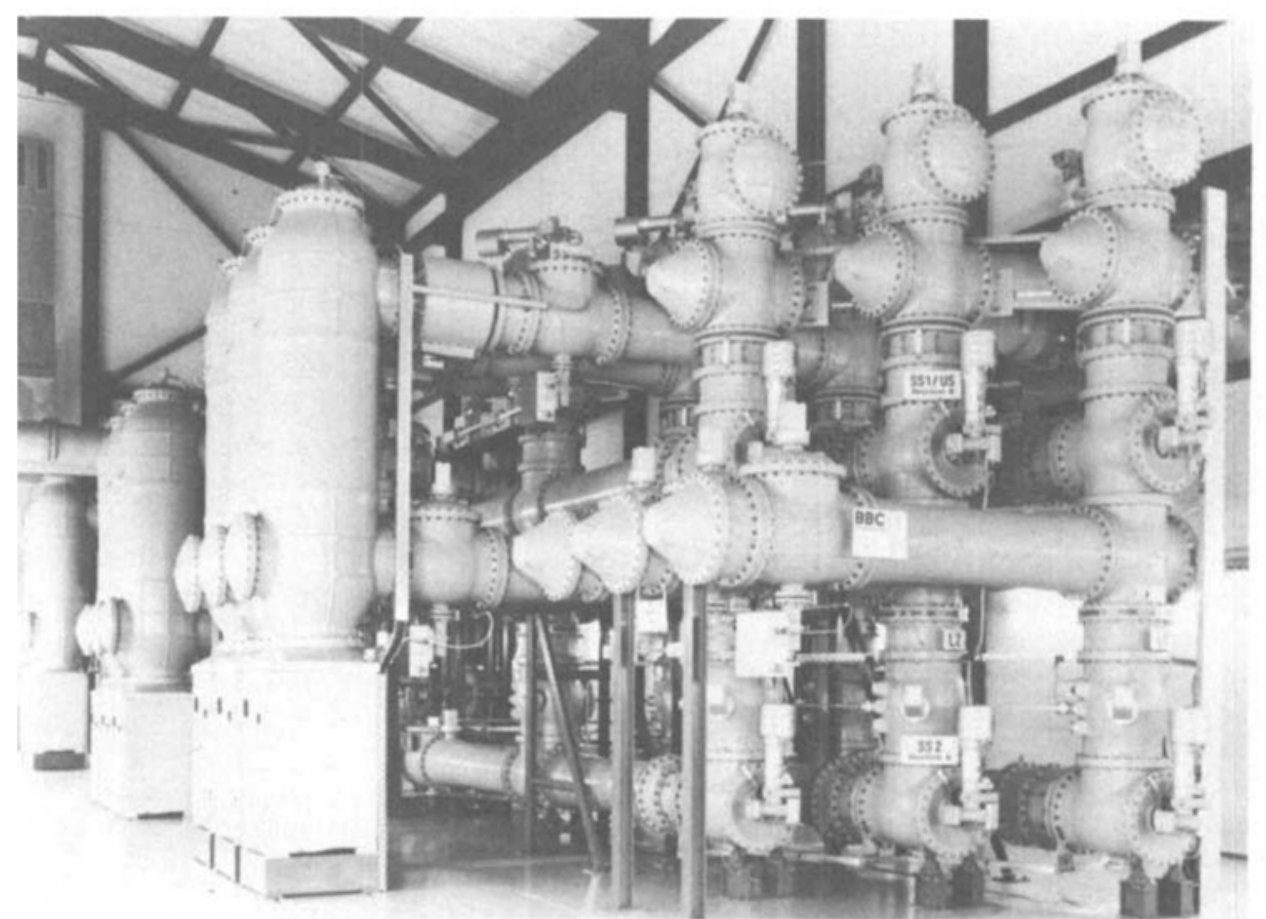

Fig. 1. High-voltage switchgear stations up to $800 \mathrm{kV}$ in GIS-technology $\left(\mathrm{SF}_{6}\right.$ gas-insulated and fully enclosed) require much less space than their air-insulated counterparts 
will be drawn regarding engineering and design of epoxy resin components and the practical value of particle surface treatment.

\section{Role of Particle-Matrix Interface: General Aspects}

\subsection{Technological Experience}

During recent years, there has been a growing interest in a 'scientific understanding' of interfacial structures and their influence on the macroscopic properties of composites. Some conferences have been held exclusively devoted to the interface and the interphase region [4] [5]. In contrast to earlier research work which was rather 'technological' in nature and where the chemical or physical nature of adhesion was proven by indirect evidence, recent work concentrates on the chemical and physical mechanisms. For example, surface analytical techniques are used to investigate element distributions by depth, position, chemical state, etc. or new test methods have been developed to study the fibre-matrix and particle-matrix adhesion and the interface micromechanics [2] [5].

Surface treatment of reinforcing inorganic filler and fibres for polymeric composites has been an 'art' or a 'know-how' which nevertheless has been very successfully applied in plastics manufacturing for many years. There are many reasons to pretreat the surface with a so-called coupling agent, most often a silane compound which is said to act as a bridge between the filler (particle or fibre) and the matrix.

In fibre-composites manufacturing for example, the fibre-coating technology has been chosen to ensure handleability of the fibres as well as compatibility with the matrix, the application, and the fabrication process. Particularly, mechanical strength and resistance against environmental influences can be improved with a good adhesion between fibre and matrix. Many papers deal with the selected aspects of surface treatment and interface examination, e.g. the chemistry and the specific properties of silane coupling agents [6] [7], surface analytical techniques [8], or interface vs. interphase discussion [9]. Other authors focus on the relevance of a good adhesion in the failure process [10] or review all the interfacial aspects in fibre reinforced plastics [11] [12].

In particulate-filled composites too, coupling agents are generally considered to provide improved mechanical strength and chemical resistance. In addition, surface treatment may improve the wetting properties and, therefore, improve the dispersion behaviour of a filler. Furthermore, water absorption generally is reduced and outdoor performance improved by a proper surface treatment of the inorganic filler.

Although the picture is not fully consistent, surface treatment of filler in thermoplastic matrices (among other factors) in- fluences the ultimate tensile strength [14] or the tensile yield stress [15] in the expected way: increased specific surface implying more well adhering polymer increases the tensile yield stress, or reduction of the filler surface tension (implying a worse adhesion) resulted in a lower tensile yield stress and lower ultimate strength. An increase of $50-100 \%$ in flexural and impact strength is reported for example for silica-filled PMMA [16].

\subsection{Particulate Epoxies}

Also in thermoset applications debonding between filler and matrix is one of the three competing damage mechanisms occurring during deformation and fracture. Depending mainly on the temperature, deformation rate, stress state, and filler content, either brittle fracture, debonding, or shear yielding dominates [2]. Brittle fracture is favoured by low temperature, high deformation rate, tensile stress state, and high filler content, whilst shear yielding is promoted by high temperature, low deformation rate, and low filler content, or by a compressive stress state. Debonding and shear yielding often occur simultaneously. Debonding obviously should be influenced by the quality of interfacial adhesion. However, the picture that can be drawn of the real advantages of silane treatment is not a simple and consistent one.

Silane-treated quartz flour for example shows the following advantages as compared with untreated samples [16]: first, the adsorption of water during storage of the filler is drastically reduced, thus, rendering the drying step unnecessary in certain applications. In electrical applications especially, the detrimental influence of moisture on dielectric breakdown is drastically reduced by silane treatment. Secondly, rheology of compounds is often affected positively. Regarding the improvement of mechanical properties by improving the interfacial adhesion, the results are somewhat controversial. The strength of alumina-filled epoxies is reported to be sensitive to the surface treatment [17]: surface treatment of alumina with a release agent (HMDS) reduced the flexural strength as compared with respective compound with nontreated filler, and the application of two different silane coupling agents resulted in increased strength values (Table 1). The toughness of the epoxy compounds, however, was not affected by the surface treatment: neither the critical stress intensity factor $K_{\mathrm{lc}}$ of alumina-filled (Table 1) [18] nor the fracture energy of
Table 2. Effect of Surface Treament on Fracture Energy of Glass-Bead-Filled Epoxy [19]

\begin{tabular}{ll}
\hline Epoxy + a 0.1 volume & Fracture energy \\
fraction glass beads & {$\left[10^{2} \mathrm{Jm}^{-2}\right]$} \\
\hline Untreated & 1.52 \\
adhesion promotor & 1.56 \\
adhesion inhibitor & 1.56 \\
\hline
\end{tabular}

glass-bead-filled epoxies vary much with the application of adhesion promoters or inhibitors (Table 2) [19]. Other authors confirm that $K_{\mathrm{lc}}$ values are not sensitive to surface treatment in glass-bead-filled epoxies, however, a good adhesion is necessary in order not to lose too much strength of the composite with increasing filler content [20]. Tentatively, one might deduce from the few results available that poorly bonded particles reduce strength and promote unstable crack growth, i.e. promote crack dip blunting which favours the stickslip mode of crack growth [18] [20]. By introducing a third elastomeric phase into these composites, other toughening mechanisms than crack dip blunting can be activated, for example cavitation of rubbery particles and shear yielding. A very common way to introduce the elastomer phase is the addition of a carboxyl-terminated copolymer of butadiene and acrylonitrile

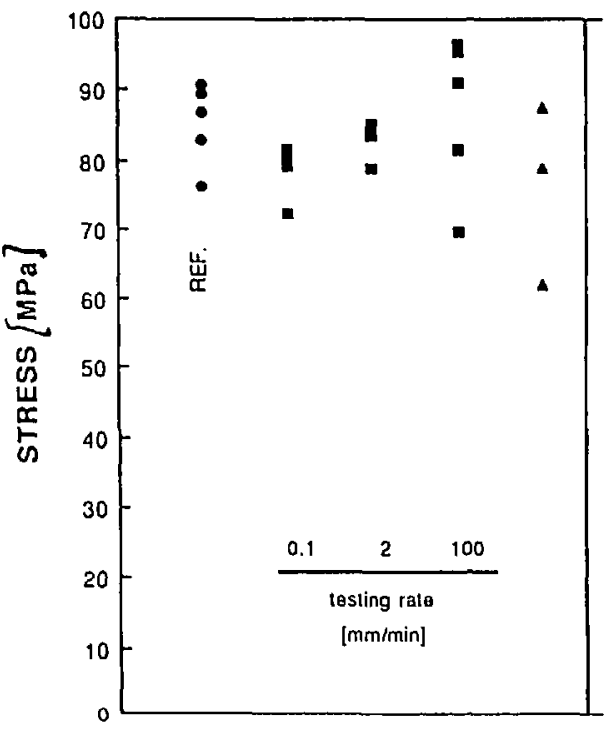

Fig. 3. Influence of pre-stressing at $85^{\circ}$ and related 'damage' on the short-term strength of a quartz flour-filled epoxy at room temperature [3]. - Virgin reference sample tested at a strain rate of $2 \mathrm{~mm} / \mathrm{min}, \mathbf{a}$ pre-stressed (corresponding to a strain of $4 \%$ ) at $85^{\circ}$ and tested at various strain rates, $\Delta$ : thermally annealed after prestressing.

Table 1. Effect of Surface Treatmem on Strenght and Toughness of Alumina-Filled Epoxies [17]

\begin{tabular}{lllccl}
\hline Resin & Filler & Treatment & Flexural strength [MPa] & Tensilc [MPa] & $K_{\mathrm{c}}\left[\mathrm{MPa} \cdot \mathrm{m}^{1 / 2}\right]$ \\
\hline $\mathrm{A}$ & $\mathrm{Al}_{2} \mathrm{O}_{3}$ & None & - & $\ldots$ & 1.86 \\
& $30 \%$ & HMDS & 107 & $\ldots$ & 1.81 \\
& & $\mathrm{~A} 187$ & 155 & - & 2.04 \\
& & All00 & 145 & - & 1.99 \\
$\mathrm{~B}$ & $\mathrm{Al}_{2} \mathrm{O}_{3}$ & None & 96 & 45 & 1.53 \\
& $30 \%$ & HMDS & 82 & - & 1.46 \\
& & A187 & 132 & 88 & 1.64 \\
& Al100 & 136 & - & 1.67 \\
\hline
\end{tabular}


Table 3. Parameters Determining the Modulus, Toughness, and Strength of Particulate-Filled Epoxies [23]

\begin{tabular}{llll}
\hline Property & Effect on & & \\
& Modulus & Fracture toughness & Strength \\
\hline Increase volume filler & + & $\left.+^{\mathrm{a}}\right)$ & $0,-^{\mathrm{b}}$ ) \\
Increase particle size & $\left.0,-{ }^{\mathrm{c}}\right)$ & 0 & - \\
Increasc aspect ratio & $?$ & + & + \\
Increase strength and modulus filler & + & + & + \\
Improved adhesion & 0 & $0^{\mathrm{d}}$ & + \\
Tougher matrix & $\left.-{ }^{\mathrm{c}}\right)$ & + & - \\
\hline
\end{tabular}

+ : increase, 0 : constant, - : decrease.

a) A plateau may be reached ( $c f$. text).

b) Dependent on strength of filler and adhesion ( $c f$. text)

c) Small decrease.

d) Change in fracture mode possible ( $c f$. text).
(CTBN) with subsequent phase separation during gelation [21]. An other quite recent way is to modify the 'interface' by introducing a thin rubbery interlayer between filler and matrix [22]. This interlayer is applied to the filler as a coating prior to mixing with resin and hardener. With both ness can be achieved.

An attempt to give a simple and generalized picture on the parameters (including interfacial adhesion) determining the modulus, toughness, and strength particulate filled thermosets has been made in Table 3 [23]. However, there are many exceptions, and it is doubtful, whether a clear picture can be drawn in due course, especially concerning the role of the interface and the interfacial adhesion. Particularly, recent strength data for silica-filled epoxies do not simplify the picture, they even indicate that the introduction of real debonding (extensive stress-whitening) by pre-stressing at elevated temperature does not, for example, really affect the ultimate strength at room temperature (Fig. 3) [3]. methods, substantial increase in though-

\section{Role of Interface in Crack Initiation and Propagation}

\subsection{Fractography}

One way to examine the role of interface in crack initiation and propagation phenomenologically, of course, is by analyzing fracture surfaces. Fig. 4 shows a typical scanning electron micrograph of a fracture surface of a silica-filled epoxy resin with untreated filler (silica filler as supplied and dried for $>16 \mathrm{~h}$ at $160^{\circ}$ ). The sample has been especially prepared to show debonded particles as well as particles with well adhering matrix, i.e. to demonstrate adhesive as well as cohesive failure. Particle fracture, a third crack propagation mechanism also has a certain importance in the presence of week particles such as dolomite [18]. Whether adhesive or cohesive failure occurs is primarily determined by the crack velocity (Fig. S). Slow crack propagation velocities and high temperature promote adhesive failure, while fast crack propagation and low temperature favours cohesive failure [1] [24]. The so-

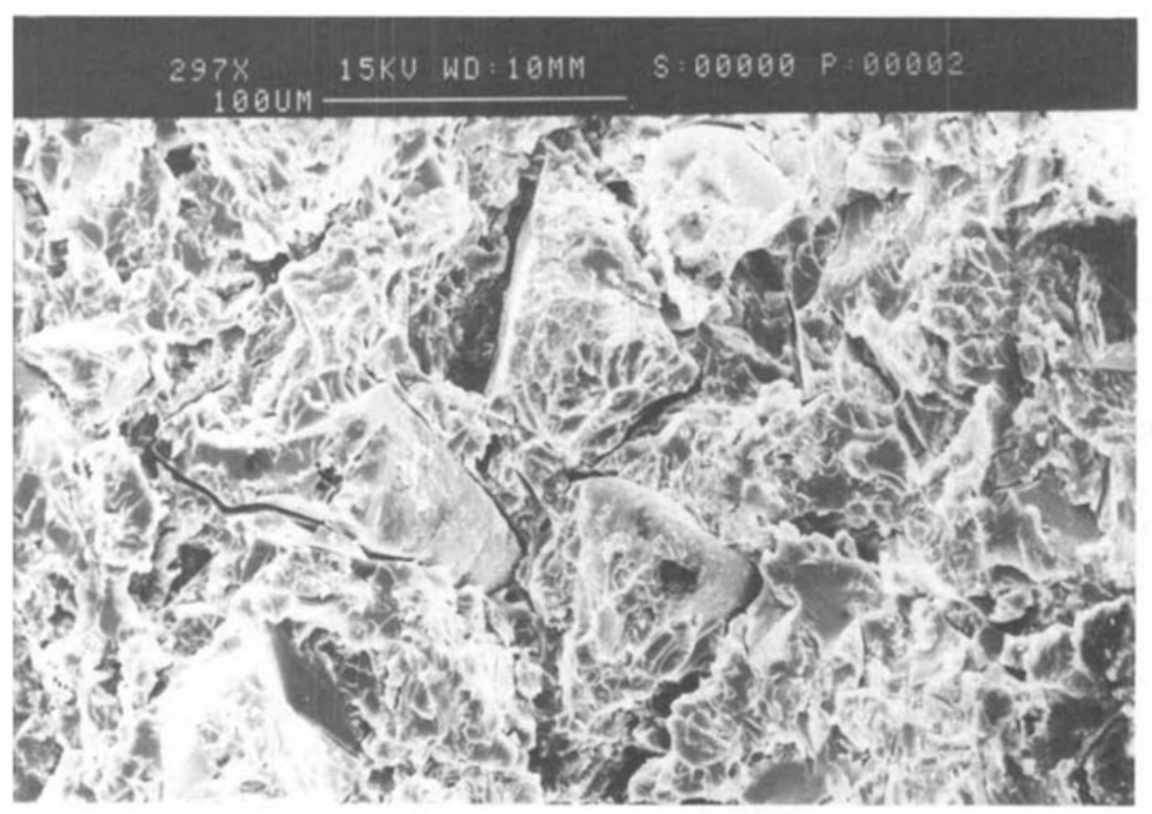

Fig. 4. SEM-Micrograph showing a fracture surface of a silica-filled epoxy. Both types of particles are visible: fully debonded as well as matrix-covered. Making use of the correlation between crack velocity, stress state and damage mechanisms described in Sect. 3 and 4, such a fracture surface can be generated: first the sample was compressed until significantly whithened, then it was impact fractured. The first step produces deponding, in the step the crack is forced to propagate through the matrix.

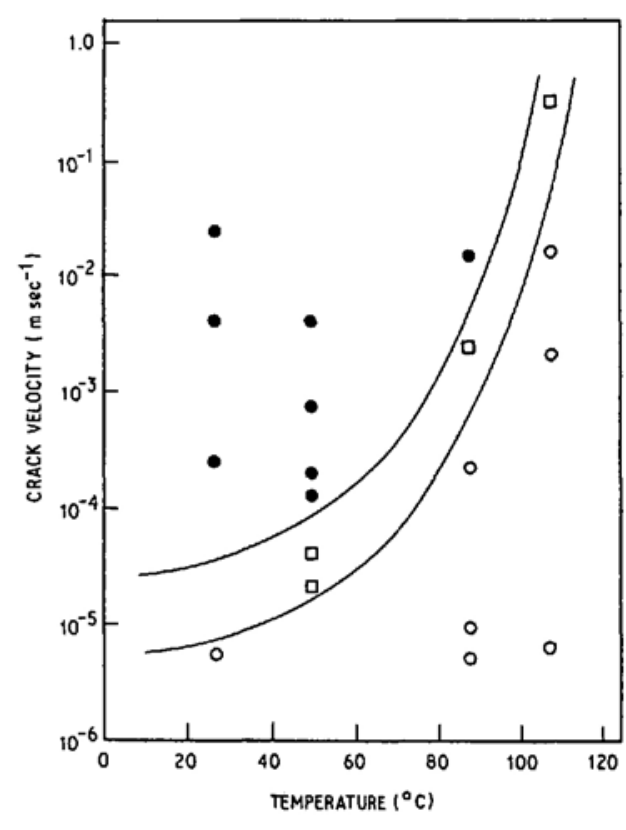

Fig. 5. The effect of crack velocity on particle-matrix dehonding. $\bullet:$ Well-bonded, $\square]$ : partially bonded, $\mathrm{O}$ : debonded.

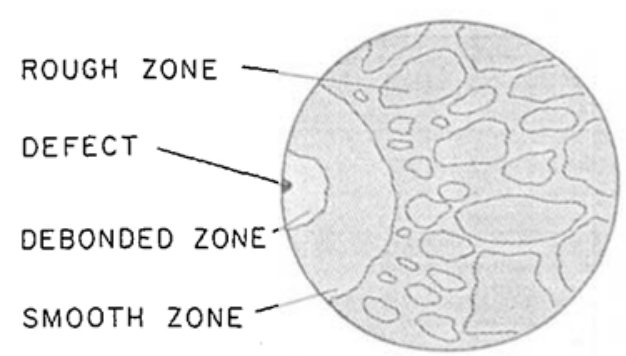

Fig. 6. Regions on the fracture surface in the filled epoxy

called debonded area in a fracture surface which is produced by slow crack growth and adhesive failure plays an important role as will become clear from the following generalized fractographic interpretation.

Fig. 6 presents a schematic diagram of the fracture surface of a typical filled resin [24]. Beside the defect (which is not always evident), it highlights three zones: a debonded zone, a smooth zone, and a rough zone. The size of these zones varies with loading conditions and test temperature, and - in certain cases - the rough zonc is fully absent. The radius of the debonded region surrounding the point of crack initiation increases with temperature and with decreasing load in a static fatigue experiment, i.e. increases with the time of loading. Crack growth is by adhesive failure (Fig. 7a). It turned out that the size of the debonded zone is a crucial parameter in controlling the static fatigue lifetime in these materials (see Sect. 3.2). The smooth zone is a relatively flat, featureless zone surrounding the debonded zone. Its size increases with temperature and decreasing applied load. The crack front proceeds through the matrix, i.e. the failure is cohesive (Fig. $7 b$ ). A detailed examination of the crack velocity revealed that the region corresponds to the crack acceleration 
a)

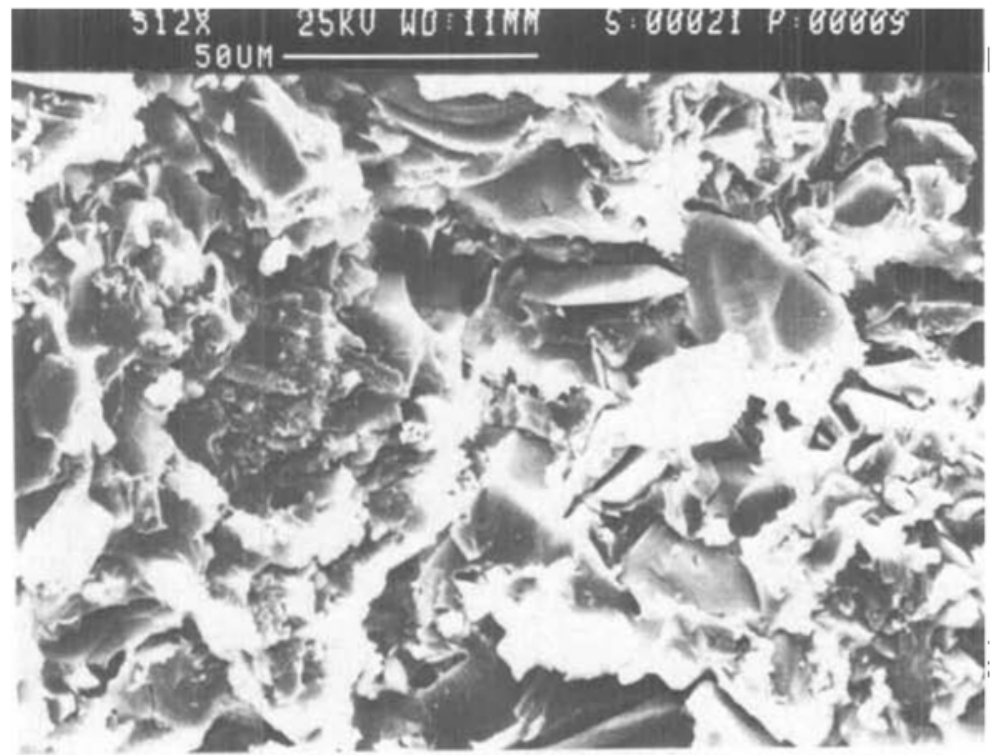

b)

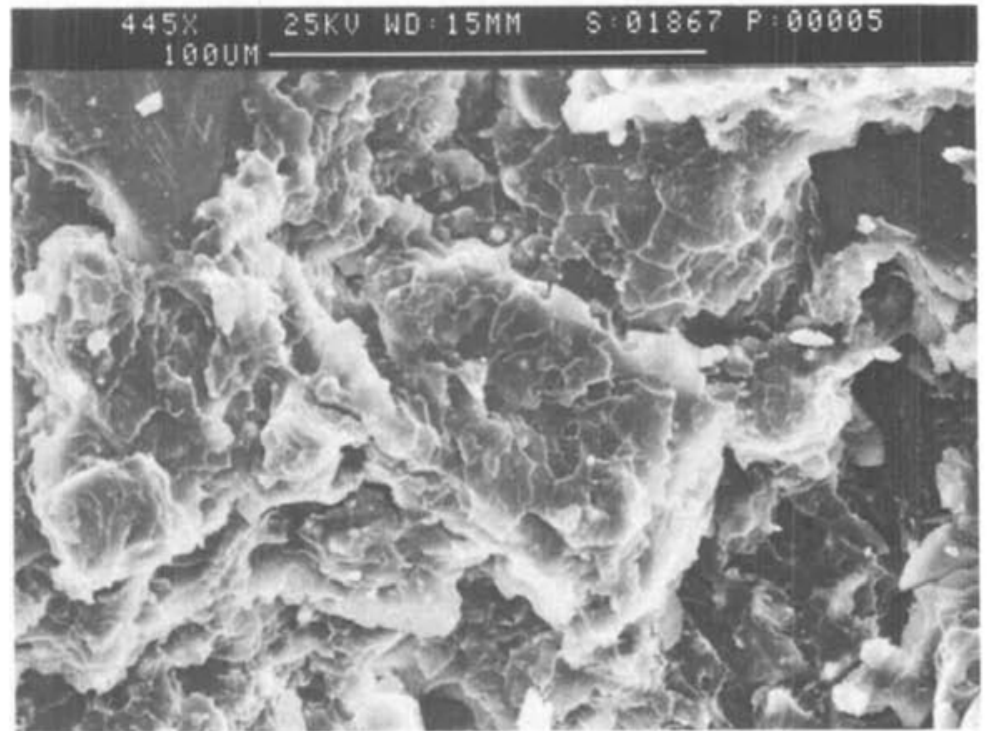

c)

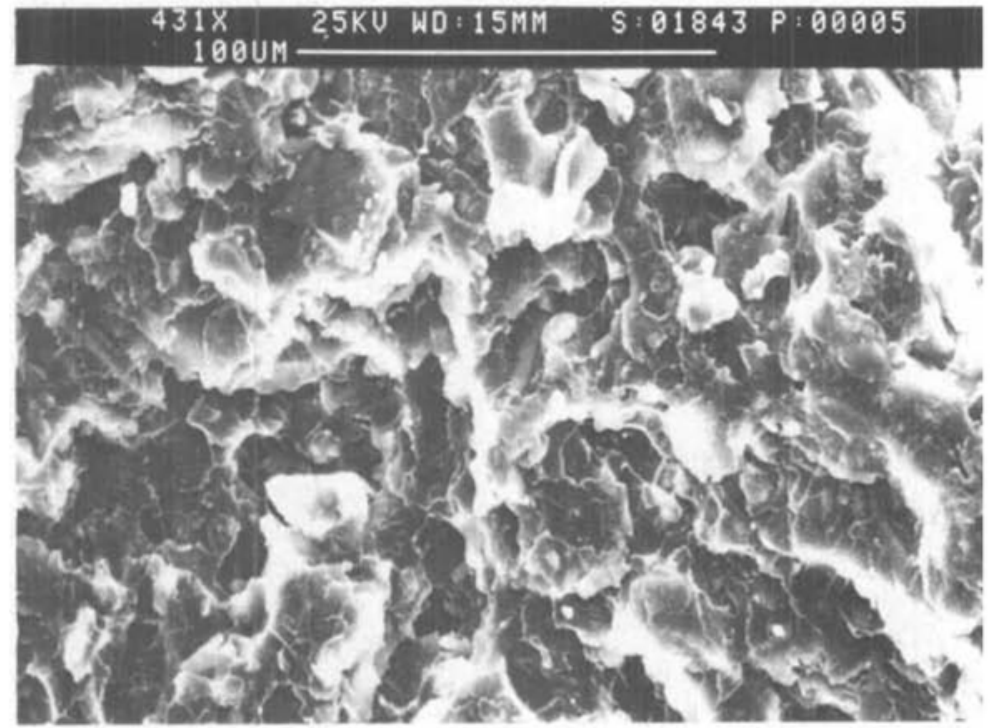

Fig. 7. Typical SEM micrographs of the various regions on the fracture surface of filled epoxies. a) Debonded region; $b$ ) smooth region at $50^{\circ} ; c$ ) rough region at $85^{\circ}$.

phase [24]. And, finally, the rough zone has a withened, three-dimensional appearance which is indicative of high-velocity crack branching Fig. 7c. Thus, the excess energy available after accelerating the crack to its maximum velocity in the material is dissipated in crack branching. should be observable in the fracture surface. A graphic representation of $\sigma Y(\sigma$ is tensile strength, $Y$ is the geometric factor for an edge-notched sample) $v s$. the inverse of the square root of the debonded zone size of various fractured specimens revealed the correct toughness $K_{\mathrm{Ic}}$ of the material (Fig. 8). Hence, proving that the debonded zone can be identified with the region of subcritical crack growth and, thus, with the critical flaw size in Eqn. I [1] [24].

$K_{\mathrm{lc}}=\sigma Y a^{1 / 2}$

\section{Role of Interface in Creep Failure}

\subsection{Creep Damage and Creep Failure}

One aspect of creep damage in filled epoxies is often visible with the naked eye in the form of stress-whitening. Stress whitening is due to microvoiding caused by the application of stress, and microvoiding mainly occurs at the filler-matrix interface. A second major deformation-induced creep damage mechanism is shear yielding. Particle fracture and matrix cracking are mechanisms of minor importance. For a silica-filled, anhydride-cured epoxy, deformation-induced damage and creep-failure mechanisms have been thoroughly investigated by Smith and coworkers [1] [26]. From their work, the following picture can be drawn: in spite of the predominantly brittle behaviour of filled epoxy resins, considerable 'ductility' (better: strain) is possible, when brittle failure is suppressed

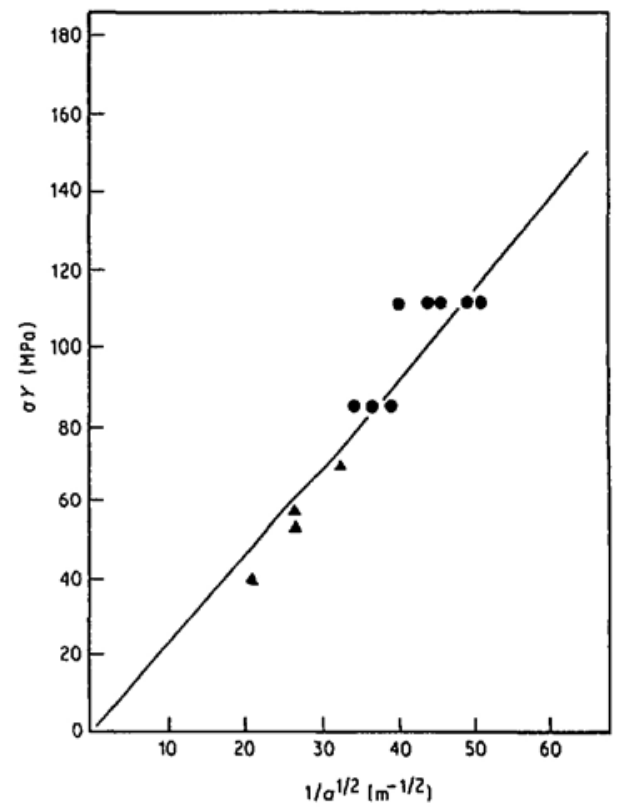

Fig. 8. Fracture-mechanics correlation between 'debonded zone size' from fractographic analysis of $(\mathbf{0})$ creep tests and $(\mathbf{\Delta})$ single-edge notch tests and strength $(T=$ $85^{\circ}$ ). If the radius of debonded zone is interpreted as the critical flaw size in linear elastic fracture mechanics, the correct $K_{\mathrm{lc}}$ value of the material results, thus, proving the fractographic interpretation of the debonded zone as being the region of subcritical crack growth. 


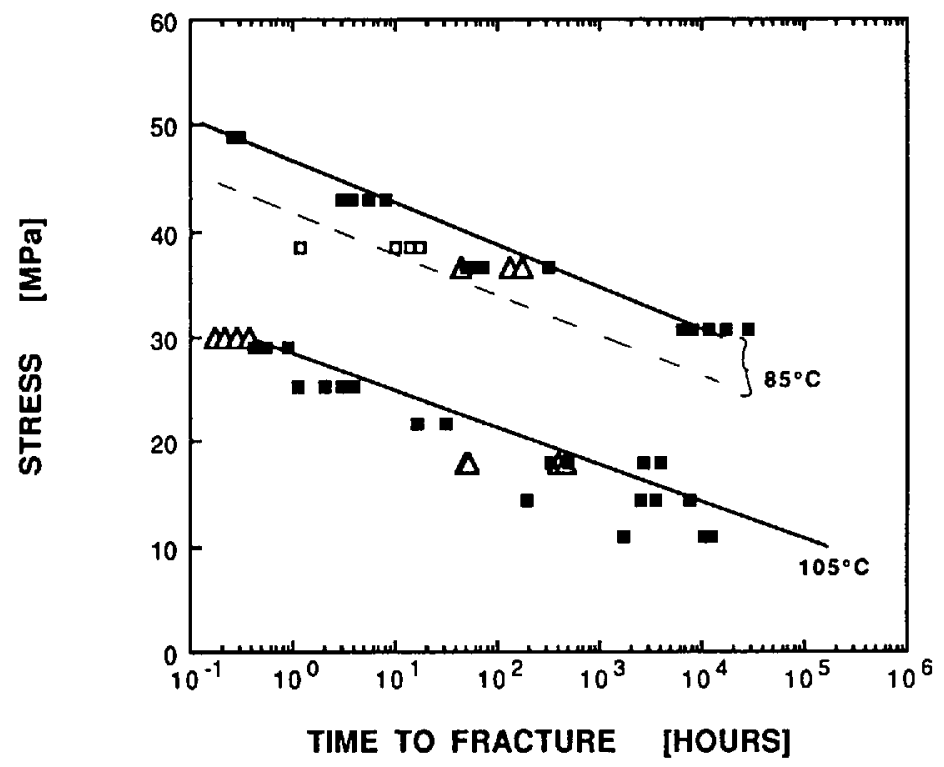

Fig. 9. Static fatigue life and interfacial adhesion at elevated temperature $\left(85^{\circ}\right.$ and $\left.105^{\circ}\right)$. Silica-filled epoxy without special surface treatment, $\Delta$ : with silane-treated silica, $\square$ : with pre-stressed (stress-whitened, and, thus, damaged sample having a large extend of debonded filler particles).

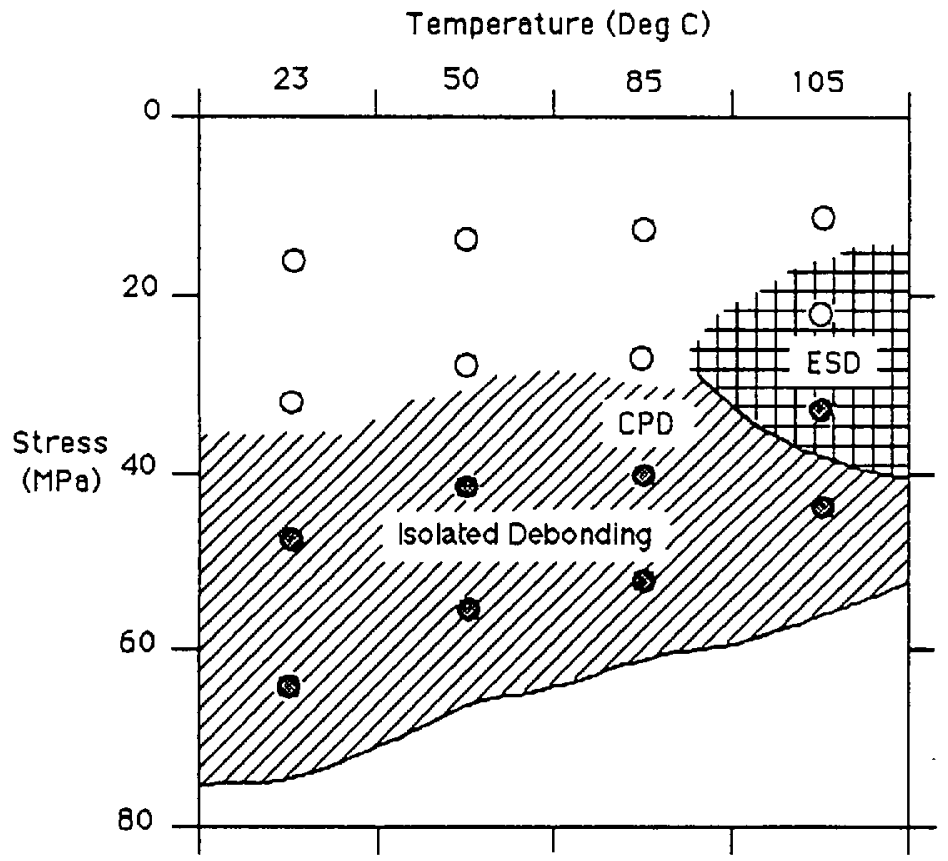

Fig. 10. Failure-mechanisms map showing the stress-temperature dependence of damage and failure in a silica-filled epoxy during a measuring time of up to two years. ESD: Extensive shear yielding and debonding. CPD: Crack propagation by debonding. Unbroken specimen. Broken specimen.

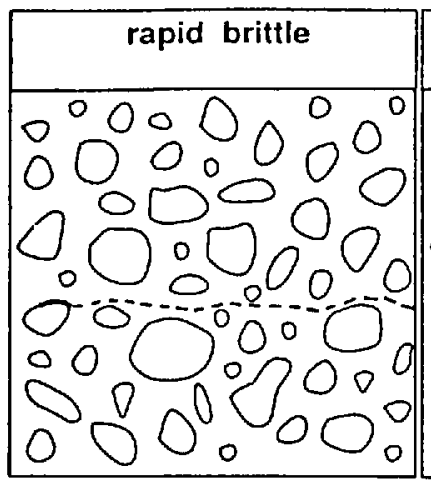

volume damage

(no)

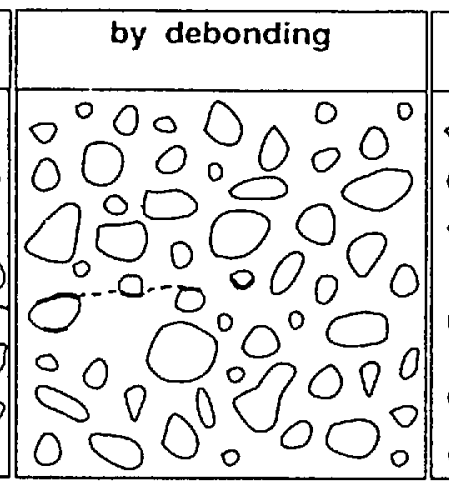

limited

(isolated debonding)

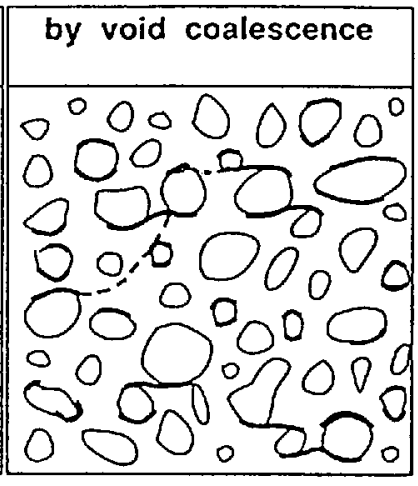

extensive

(stress - whitening)
Fig. 11. Crack-propagation mechanisms in particulate-filled epoxies. a) Rapid brittle failure, $b$ ), crack growth by debonding, $c$ ) crack growth by void coalescence (creep failure). either by avoiding tensile stresses, by increasing the test temperature or by reducing the deformation rate.

In tension, damage (shear yielding and debonding) in filled resins could only be detected at $85^{\circ}$ and above, and at slow deformation rates. In compression, particle debonding occurs without any pronounced temperature dependence and starts at the yield point. It is always accompanied by shear yielding. The shear bands are highly birefringent and form a network at an angle of approximately $45^{\circ}$ to the principal stress direction. They may be completely recovered upon heating above the glass transition temperature of the resin. In tension, deponding occurs at the poles of the particles, in compression on particle surface planes approximately parallel to the shear plane.

Macroscopically, the material's behaviour depends on the competition between shear yielding (accompanied by deponding) and fracture. Raising the temperature and lowering the deformation rate increases the "ductility' and, thus, the notch sensitivity is reduced, permitting more damage accumulation prior to failure. Particularly in compression, brittle fracture is supressed so damage can accumulate freely. However, even if brittle fracture is supressed, the materials does not really become ductile. The contrary happens: the accumulation of damage leads to a reduction of toughness and strength on a longterm scale [1] [26]. From the data in Fig. 9 [27] for example, it can be seen how the long-term strength depends on time and temperature. It can also be seen that silanetreatment of quartz filler does not positively affect the static fatigue life and - in contrast to ultimate strength measurements at room temperature (Fig. 3) - prestressing and, thus, damage (including shear yielding debonding) can reduce fatigue life by a factor of ten. Here again, the expected improvement by a filler surface treatment could not be observed, although the lack of adhesion, i.e. a considerable amount of debonding, clearly results in a deterioration of the creep life.

\subsection{Engineering Implications of the Creep} Behaviour: Failure-Mechanisms Maps

In Fig. 10 an attempt has been to represent some of the above findings in a pictorial way which is also useful for practical purposes. These damage-mechanisms maps show the temperature-stress dependence of damage and failure of the examined silica-filled epoxy within an experimental time of two years. The solid circles correspond to broken specimens, the unfilled represent test that were interrupted prior to fracture. Three main zones can be identified: first, the cross-hatched area where extensive shear yielding and debonding (ESD) has been identified; secondly, the cross-barred region with isolated debondings where the crack propagates by debonding (CPD); and, thirdly, the save zone, the area at low loads where no 
damage was visible, and no fracture occurred within the test time. For engineering applications, this kind of representation is very useful and indicates the long-term load bearing capability of the epoxy resin.

\section{Conclusions}

The role of filler-matrix interface in particulate epoxies has been reviewed. Special attention has been given to the effect of debonding, i.e. adhesive failure, on crack initiation, crack propagation, and creep failure. A brief representation of the three principal crack propagation modes in filled epoxies is give in Fig. 11 ; rapid brittle failure is dominant at low temperatures and high strain rates. A single debonding event might be sufficient to initiate rapid brittle fracture through the matrix. In an intermediate region (higher temperatures and/or lower strain rates), the crack propagates by debonding: the plastic deformation around the crack tip induces debonding at filler grains slightly ahead of the tip. Close to the viscoelastic transition and at very low strain rates, the increased compliance of the matrix lead to global debonding and to a crack propagation by 'void coalescence'. Obviously, crack propagation through damaged material is less energyconsuming, and toughness is reduced.

The effect of surface treatment on various macroscopic properties can be summarized as follows: the results in the literature indicate that often a significant improvement can be achieved. However, since rules with a sufficient reliability are still lacking, every single situation has to be considered separately. In particular, very few data are available on the influence of filler surface treatments on the balance between toughness and strength and on the creep behaviour.
[1] W. J. Cantwell, J.W Smith, H.H. Kausch, T Kaiser, 'Examination of the processes of deformation and fracture in a silica-filled epoxy resin', $J$ Mater. Sci. 1990, 25, 633

[2] J. W. Smith, T. Kaiser, A.C. Roulin-Moloney, 'Deformation-induced volume damage in particulate-filled epoxy resins, ,J. Mater. Sci. 1988, 23, 3833.

[3] A. Reicharz, A. Demarmels, 'Damage characterization in silica filled epoxy resins', to be presented at EPF '90, 3rd Eur. Fed. Symp. on Polym. Mat, Sorrento; Italy, Sept. 24-28, 1990.

[4] Interfaces in Polymer, Ceramic, and Metal Matrix Composites', Proc. 2nd lntern. Conf. on Composite Interfaces (ICCI-II), June 13-17, 1988 , Cleveland, Ohio, Ed. H. Ishida, Elsevier Science Publishing Co., Inc., New York, 1988.

[5] 'Interfacial Phenomena in Composite Materials '89', Proc. Conf. from Sept. 5-7, 1989, Sheffield, UK, Ed. F.R. Jones, Butterworths, London, 1989

[6] E.P. Plueddemann, 'Silane Coupling Agents', Plenum Press, New York, 1982.

[7] E.P. Plueddemann, 'Present status and research needs in silane coupling', in 'Interfaces in Polymer Ceramic, and Metal Matrix Composites', Ed. H. Ishida, Elsevier Science Publishing Co.. Inc., New York, 1988, p. 17

[8] J.E. Castle, J.F. Watts, 'Surface analytical techniques for studying interfacial phenomena in composite materials', in 'Interfacial Phenomena in Composite Materials '89', Ed. F. R. Jones, Butterworths, London, 1989, p. 3.

[9] J. L. Thomans, J. B. W. Morsink, 'Investigation of the Interphase in Glass-Fibre-Reinforced Epoxy Composites', in 'Interfaces in Polymer, Ceramic and Metal Matrix Composites', Ed. H. Ishida, Elscvier Science Publishing Co., Inc., New York, 1989, p. 503

[10] 'The failure of reinforced plastics', Ed. F.L. Matthews, Mechan. Engin. Publ Limited, London. 1990.

[11] L. K. English, 'Fabricating the Future with Composite Materials', Part IV: 'The Interface', Materials Engineering, p. 43, March 1987.

[12] F. R. Jones, 'Interfacial aspects of glass fibre reinforced plastics', in 'Interfacial Phenomena in Composite Materials '89', Ed. F. R. Jones, Butterworths, London, 1989, p. 25.

[13] A. M. Adur, R. C. Constable, J. A. Humenik, 'Use of Acrylic Acid-Modified Polyolefins to Improve Performance Properties of Mica Filled Polyolefins', 43rd Ann. Conf. Comp. Inst. SPI, Febr. 1.5, 1988, session 7-C. p. 1 .
[14] B. Pukánszky, 'Interface interactions and strength of particulate filled thermoplastics', in 'Interfacial Phenomena in Composite Materials', Ed. F.R. Jones, Butterworths, London, 1989, p. 201.

[15] B. Pukánszky, B. Turcsainyi, F. Tüdös, 'Effect of interfacial interaction on the tensile yield stress of polymer composites', in 'Interfaces in Polymer. Ceramic, and Metal Matrix Composites', Ed. H. Ishida, Elsevier Science Publishing Co., Inc., New York, 1989, p. 476

[16] D. Skudelny, 'Silanisierte Füllstoffe und ihre Einsatzgebiete', Kunststoffe 1987.77, 1153.

[17] A.C. Moloney, H.H. Kausch, T. Kaiser, H.R. Beer, 'Parameters determining the strength and toughness of particulate filled epoxide resins", $J$. Mater Sci. 1987, 22, 381 .

[18] A.C. Moloney, H. H. Kausch, H. R. Stieger, 'The fracture of particulate-filled epoxide resins', $J$. Mater. Sci. 1983, 18, 208.

[19] J. Lilley, "The fracture of filled epoxy resins', Ph. D. Thesis, University of Keel, 1973.

[20] J. Spanoudakis, R.J. Young, 'Crack propagation in glass particle-filled cpoxy resin', Part 2: 'Effect of particle-matrix adhesion", J. Mater. Sci. 1984. $19,487$.

[21] R.A. Pearson, A.F. Yee, 'Toughening mechanisms in elastomer-modified epoxies", $J$. Maler. Sci. 1989, 24, 2571

[22] N. Amdouni, J.F. Gérard, H. Sauterau, X. Caux, F. Fernagut, G. Coulon, 'Coated glass beads epoxy composites: Influence of the interlayer thickness on pre-yielding and fracture properties', 20th Eur. Conf Macromol. Physics, Lausanne (Switzerland), Sept. 26 30, 1988.

23] T. Kaiser, 'Highly cross-linked polymers', Progr. Polym. Sci. 1989, 14, 373 .

[24] W. J. Cantwell, A.C. Roulin-Moloney, T. Kaiser. Fractography of unfilled and particulate filled epoxy resins', J. Mater. Sci. 1988, 23, 1615.

[25] H. R. Beer, T. Kaiser, A.C. Roulin-Moloney, H.H. Kausch, 'Static fatigue and time to failure predictions of parliculate filled epoxide resin composites', J. Mater. Sci. 1986, 2l,3661.

[26] J.W. Smith, 'Deformation induced failure mechanisms in particulate filled epoxy resins', Ph. D. Thesis No. 792 EPFL, Lausanne, 1989.

[27] A. Reicharz, A. Demarnels, T. Kaiser, ABB Corporate Research, internal reports.

\section{Physico-chemical Aspects of Fillers in Polypropylene}

\section{Hans-Peter Schlumpf*}

\section{Introduction}

Fillers and reinforcing materials for thermoplastics are generally solid additives which differ from the polymer matrix by their composition and structure. An exact differentiation, however, between fillers and reinforcing materials is difficult. In general, additives improving the tensile strength and tensile strength at break of filled polymers should be designated as reinforcing materials, whereas additive decreasing these properties are generally termed as fillers or extenders. In thermoplastics, both fillers (excluding air) and reinforcing additives have only four things in common: they increase the volume, enhance stiffness, decrease the elongation and thermal expansion, and improve the dimensional stability of the finished parts.

\section{Market Situation}

Filled polypropylene is one of the fastest growing thermoplastic material in Western
Europe and the USA. Talc is the leading filler for polypropylene followed by natural $\mathrm{CaCO}_{3}$. A low consumption for all other mineral fillers with the exception of glass fibres can be foreseen for the next years. Main applications for mineral filled polypropylene are automotive parts like heating systems, air intake or lamp housings. Injection-moulded garden furniture is actually the hottest item for talc or carbonate filled polypropylene. Electrical, business, and domestic appliances (kitchen and washing-machine parts) have a good potential too. Not to forget the application of fine carbonates in oriented polypropylene film (OPP) weaving tapes or strappings.

\footnotetext{
* Correspondence: Dr. H.-P. Schlumpf Plüss-Staufer $A C$ Baslerstrasse

$\mathrm{CH}-4665$ Oftringen
} 